\title{
Real-time Tracking of Proton Transfer from the Reactive Cysteine to the Flavin Chromophore of a photosensing Light Oxygen Voltage protein
}

Raiza N. A. Maia1, David Ehrenberg1, Sabine Oldemeyer1, Esther Knieps-Grünhagen², Ulrich Krauss ${ }^{3}$, Joachim Heberle ${ }^{1, *}$

${ }^{1}$ Freie Universität Berlin, Department of Physics, Experimental Molecular Biophysics, Arnimallee 14, 14195 Berlin, Germany;

2 Institut für Molekulare Enzymtechnologie, Heinrich-Heine-Universität Düsseldorf, Forschungszentrum Jülich, D-52426 Jülich, Germany

3 Institute of Bio- and Geosciences (IBG-1): Biotechnology, Forschungszentrum Jülich, D-52426 Jülich, Germany

* Correspondence: joachim.heberle@fu-berlin.de; Tel.: +49-30-838-56161 


\section{Contents}

1. Table S1, Fig. S1: Assignment of the vibrational bands to molecular vibrations............................

2. Fig. S2: Difference spectra in the S-H stretching vibrational range ..........................................

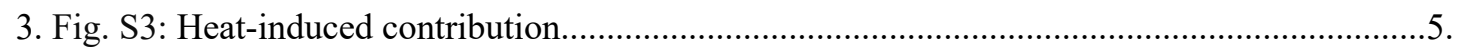

4. Fig. S4, Table S2: Global analysis of the time-resolved UV/Vis data .........................................

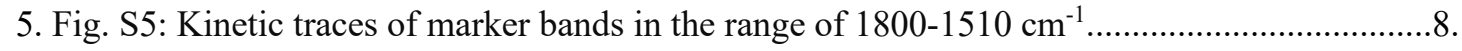

6. Fig. S6: Lifetime density analysis of the time-resolved IR data......................................................

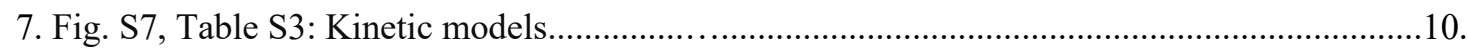

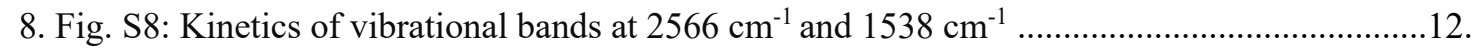

9. Fig. S9: Time-resolved spectra using rapid-scan FTIR spectroscopy ..........................................13.

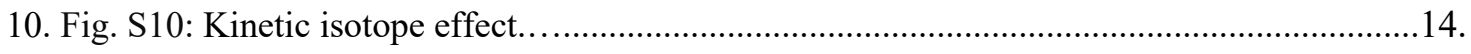




\section{Assignment of the vibrational bands to molecular vibrations}

Table S1: Band assignments of the molecular vibrations from Figure 2. The assignments were conducted based on the literature review.

$v$ : stretching mode;

$\delta$ : bending mode.

\begin{tabular}{|c|c|}
\hline $\begin{array}{c}\text { Infrared difference } \\
\text { bands }\end{array}$ & Vibrational assignment \\
\hline-2566 & S-H stretching 4 \\
\hline+1724 & $\mathrm{C}=0$ (mainly $\left.\mathrm{C}_{4}=0\right)^{8}$ \\
\hline-1710 & $\mathrm{C}=0$ symmetric stretching $\left(v \mathrm{C}_{4}=0-\text { mainly }\right)^{9-11}$ \\
\hline+1682 & $v\left(\mathrm{C}_{2}=\mathrm{O}\right), \delta\left(\mathrm{N}_{3}-\mathrm{H}\right)^{6}$ \\
\hline-1672 & $\mathrm{C}=0$ asymmetric stretching $v\left(\mathrm{C}_{2}=\mathrm{O}\right), \delta\left(\mathrm{N}_{3}-\mathrm{H}\right)^{8,10,12}$ \\
\hline+1655 & $v(\mathrm{C}=0)\left(\text { mainly } \mathrm{C}_{4}=0\right)^{7}$ \\
\hline-1645 & $v \mathrm{C}=0$ (mainly $\left.\mathrm{C}_{2}=0\right), v\left(\mathrm{C}_{10 \mathrm{a}}=\mathrm{N}\right), v(\mathrm{C}=\mathrm{C}) \operatorname{ring} \mathrm{I}^{4,9,13}$ \\
\hline+1622 & $v(\mathrm{C}=0)$ (mainly $\left.\mathrm{C}_{2}=0\right), v(\mathrm{CC})$ of ring $[7,10,14$ \\
\hline-1580 & $v\left(\mathrm{C}_{4 a}=\mathrm{N}_{5}\right), v\left(\mathrm{C}_{4}-\mathrm{C}_{4 a}\right), v\left(\mathrm{C}_{10 \mathrm{a}}-\mathrm{N}_{10}\right), v\left(\mathrm{C}_{10 \mathrm{a}}=\mathrm{N}_{1}\right)^{4,9,15-16}$ \\
\hline-1550 & $v\left(\mathrm{C}_{5 \mathrm{a}}=\mathrm{C}_{6}\right), v\left(\mathrm{C}_{8}-\mathrm{C}_{9}\right), v\left(\mathrm{C}_{10 \mathrm{a}}=\mathrm{N}_{1}\right), v\left(\mathrm{C}_{4 \mathrm{a}}=\mathrm{N}_{5}\right){ }^{4,9,15}$ \\
\hline+1533 & $v\left(\mathrm{C}_{4 \mathrm{a}}-\mathrm{N}_{5}\right), v\left(\mathrm{C}_{5 \mathrm{a}}-\mathrm{N}_{5}\right), v\left(\mathrm{C}_{10 \mathrm{a}}=\mathrm{N}_{1}\right), \delta\left(\mathrm{CH}_{3}\right)^{13,17}$ \\
\hline+1514 & $v(\mathrm{CC}), v(\mathrm{CN})^{14,17}$ \\
\hline+1454 & $v\left(\mathrm{C}_{2}-\mathrm{N}_{1}\right), v\left(\mathrm{C}_{2}-\mathrm{N}_{3}\right), v\left(\mathrm{C}_{4 \mathrm{a}}=\mathrm{C}_{4}\right), \delta\left(\mathrm{CH}_{3}\right){ }^{18}$ \\
\hline+1425 & $v\left(\mathrm{C}_{4 \mathrm{a}}=\mathrm{C}_{10 \mathrm{a}}\right){ }^{17}$ \\
\hline-1404 & $v\left(\mathrm{C}_{4}-\mathrm{N}_{3}\right), v\left(\mathrm{C}_{4}-\mathrm{C}_{4 \mathrm{a}}\right), v\left(\mathrm{C}_{2}-\mathrm{N}_{3}\right), \delta\left(\mathrm{C}_{9}-\mathrm{H}\right), \delta\left(\mathrm{C}_{4}=0\right) 15-16,19$ \\
\hline+1377 & $v\left(\mathrm{C}_{10 \mathrm{a}}-\mathrm{N}_{10}\right), \delta\left(\mathrm{N}_{3}-\mathrm{H}\right){ }^{20}$ \\
\hline-1350 & $v\left(\mathrm{C}_{10 \mathrm{a}}-\mathrm{N}_{10}\right), v\left(\mathrm{C}_{1}-\mathrm{N}_{10}\right), v\left(\mathrm{C}_{5 \mathrm{a}}-\mathrm{C}_{9 \mathrm{a}}\right), v\left(\mathrm{C}_{10 \mathrm{a}}=\mathrm{C}_{4 \mathrm{a}}\right){ }^{9,15}$ \\
\hline+1301 & $v\left(\mathrm{C}_{2}-\mathrm{N}_{1}\right), v\left(\mathrm{C}_{2}-\mathrm{N}_{3}\right)^{20}$ \\
\hline-1270 & $v\left(\mathrm{C}_{5 a}-\mathrm{N}_{5}\right){ }^{11,21}$ \\
\hline-1248 & $v\left(\mathrm{C}_{4}-\mathrm{N}_{3}\right), v\left(\mathrm{C}_{2}-\mathrm{N}_{3}\right), v\left(\mathrm{C}_{4}-\mathrm{C}_{4 a}\right), v\left(\mathrm{C}_{2}-\mathrm{N}_{1}\right), \delta\left(\mathrm{C}_{2}=0\right) 9,15,17$ \\
\hline-1221 & $\left.\mathrm{C}_{4 a}\right), v\left(\mathrm{C}_{1}-\mathrm{N}_{10}\right), v\left(\mathrm{C}_{9 \mathrm{a}}-\mathrm{N}_{10}\right), v\left(\mathrm{C}_{2}-\mathrm{N}_{3}\right)^{9,13,1}$ \\
\hline
\end{tabular}

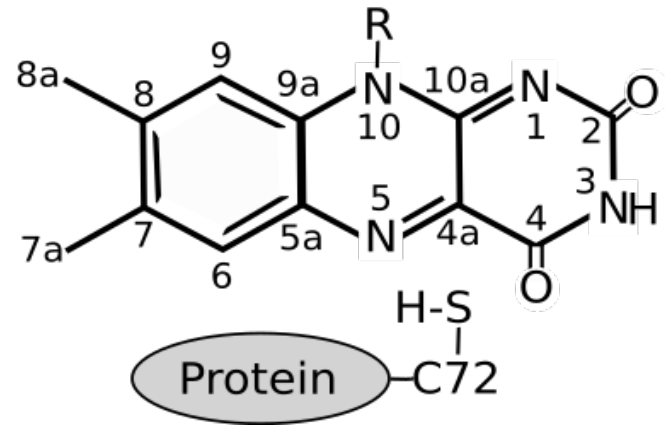

Figure S1: 7,8-Dimethyl isoalloxazine moiety of a flavin with IUPAC numbering. In FMN, R represents the ribityl side chain which is phosphorylated at $\mathrm{C}^{\prime}$ position. The reactive cysteine residue $(\mathrm{C} 72)$ of DsLOV (protein) is also depicted. 


\section{Difference spectra in the S-H stretching vibrational range}
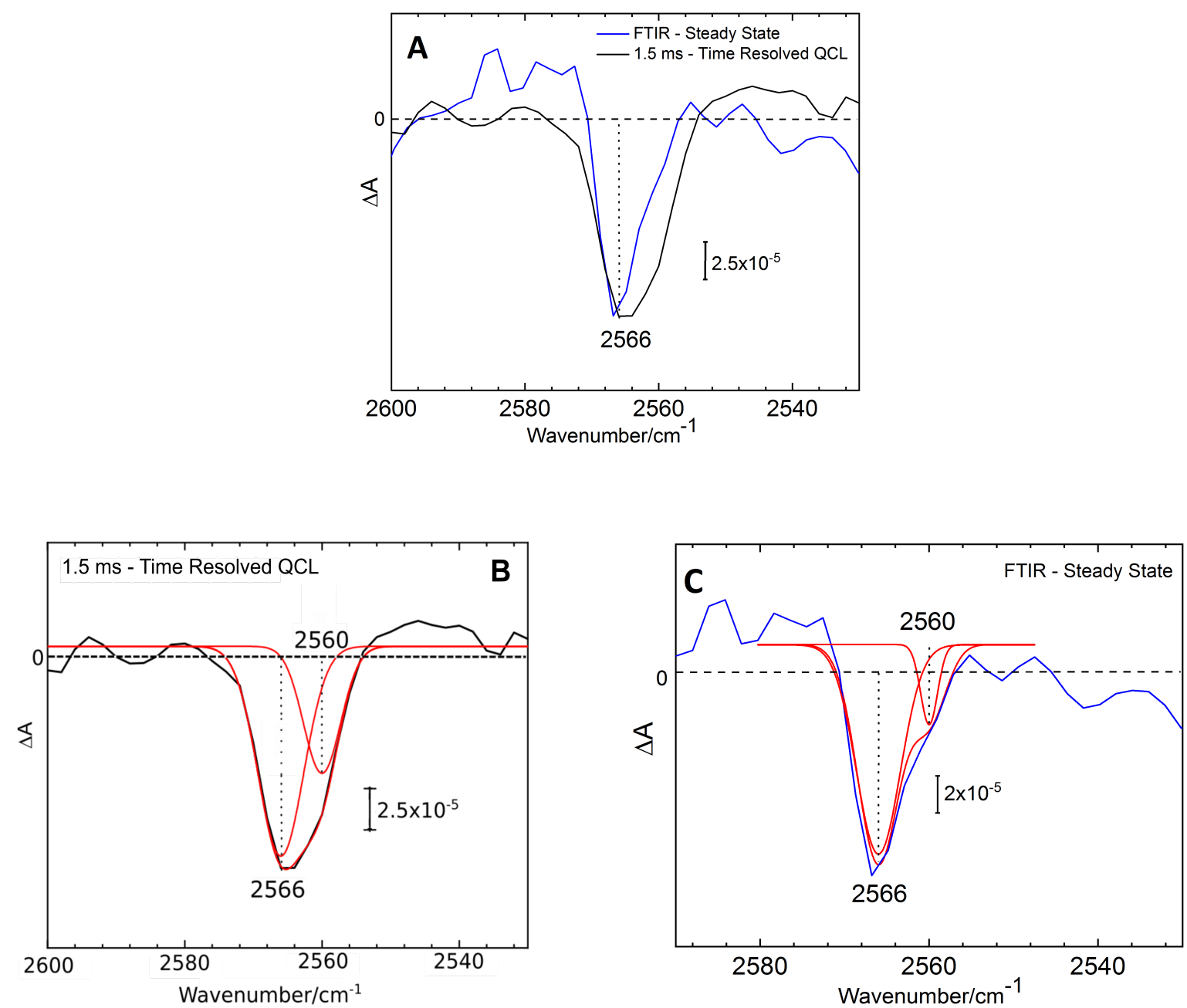

Figure S2: (A) Comparison between time-resolved QCL data at $1.5 \mathrm{~ms}$ (black spectrum) and the FTIR light minus dark difference spectrum in the range of the cysteine S-H stretching vibration (blue spectrum). Data collected from the two different experiments are in good agreement regarding the position of the S$\mathrm{H}$ band at $2566 \mathrm{~cm}^{-14}$, indicating a strong hydrogen-bonding environment. (B) IR difference spectrum at $1.5 \mathrm{~ms}$ (black) of the vibrational band of the S-H stretch of C72 of DsLOV-M49S recorded by timeresolved flash photolysis using a tunable EC-QCL. The spectrum has been fitted by the sum of two Gaussians. The relative areas are $67 \%$ for the band $2566 \mathrm{~cm}^{-1}$ and $33 \%$ for the band $2560 \mathrm{~cm}^{-1}$. (C) FTIR steady-state light minus dark difference spectrum of the vibrational band of the S-H stretch of $\mathrm{C} 72$ of DsLOV-M49S. The spectrum has been fitted by the sum of two Gaussians. The relative areas are $79 \%$ for the band at $2566 \mathrm{~cm}^{-1}$ and $21 \%$ for the band at $2560 \mathrm{~cm}^{-1}$. 


\section{Heat-induced contribution}

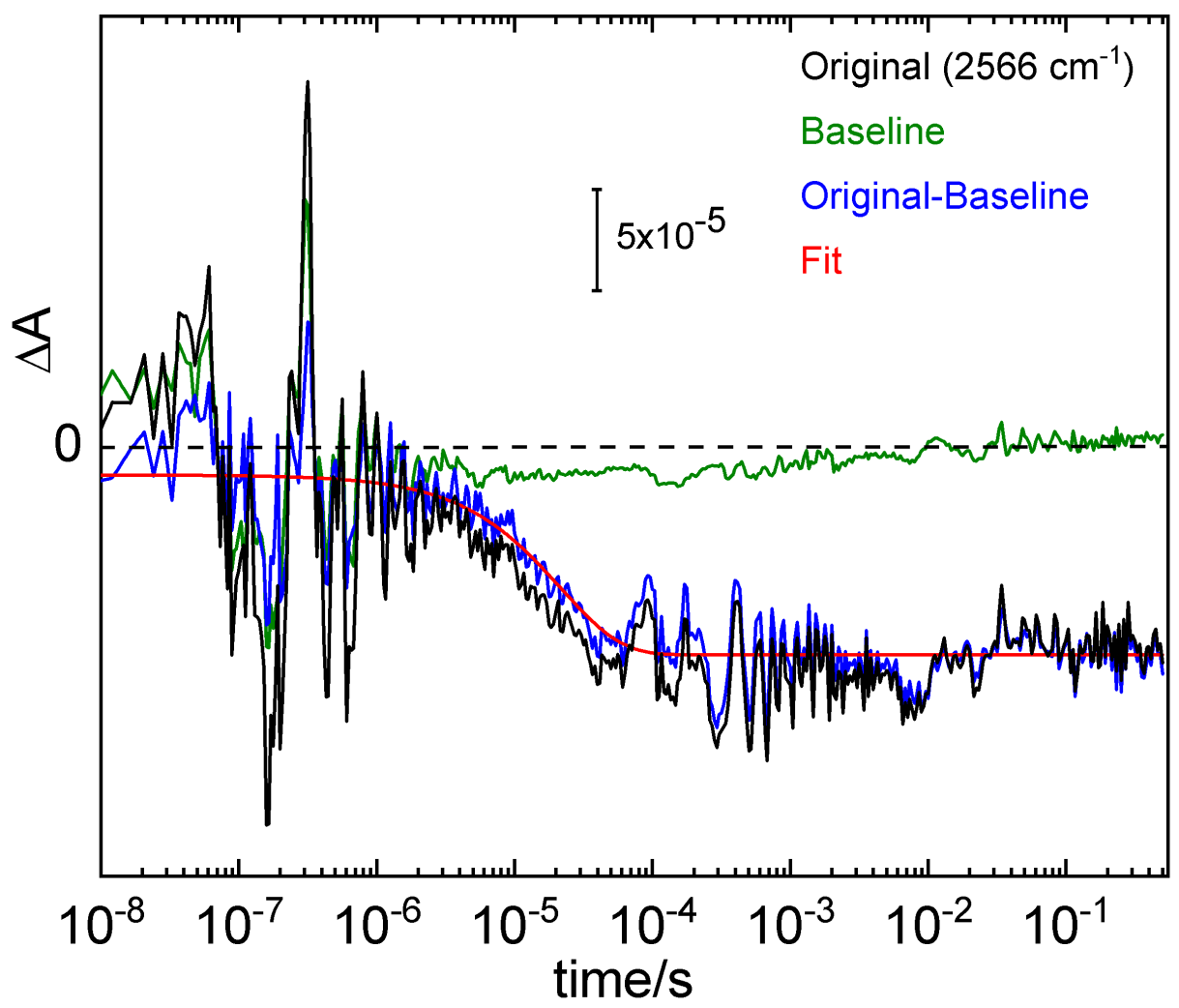

Figure S3: Subtraction of the heat-induced contribution from the kinetic trace of the S-H vibration. The original kinetic trace of the deprotonation of $\mathrm{C} 72$ at $2566 \mathrm{~cm}^{-1}$ (black trace) is overlaid by heat-induced changes of the medium (water). To elimitate this contribution, we integrated the absorption changes across the range of $2550-2520 \mathrm{~cm}^{-1}$ (green trace) which was subtracted from the original kinetics at $2566 \mathrm{~cm}^{-1}$. The differences of these time traces (in blue) has been fitted by a single exponential (red trace). 


\section{Global analysis of the time-resolved UV/Vis data}

A

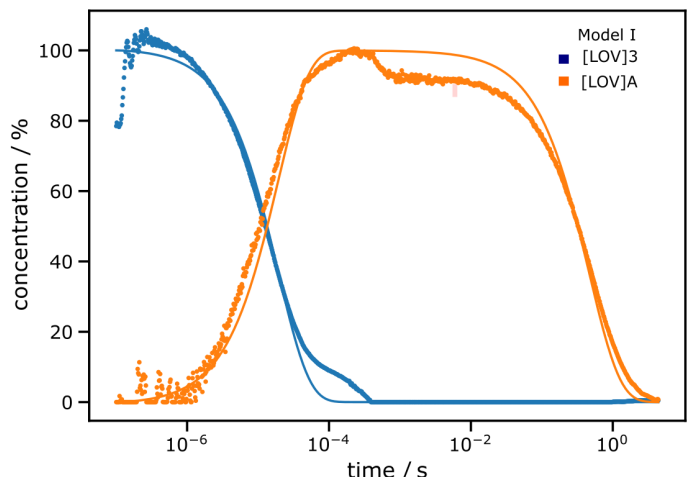

C

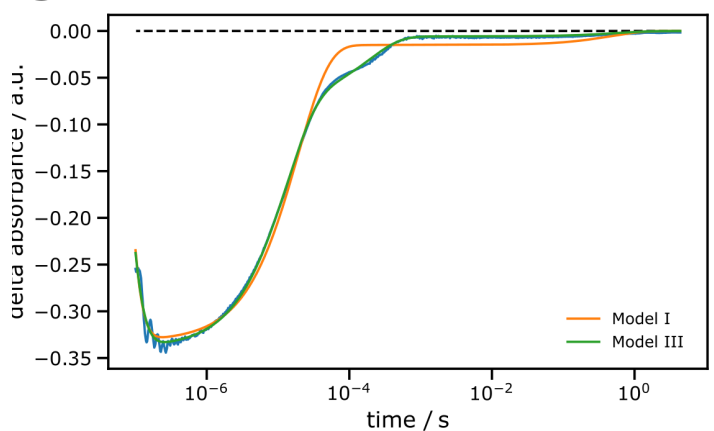

E

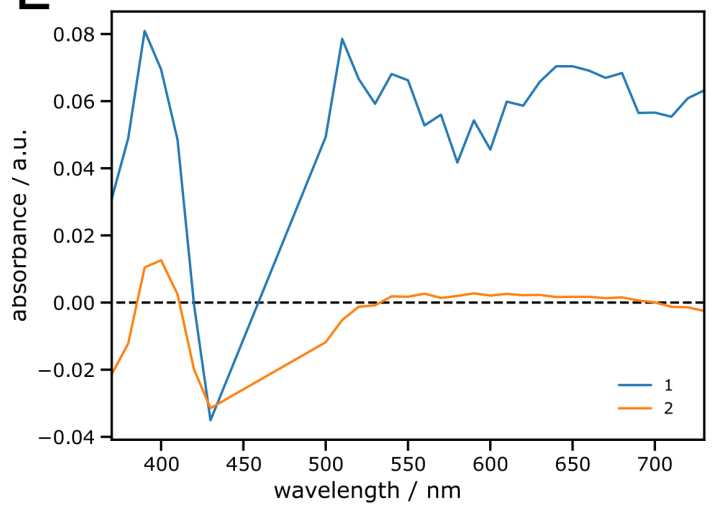

$\mathrm{B}$

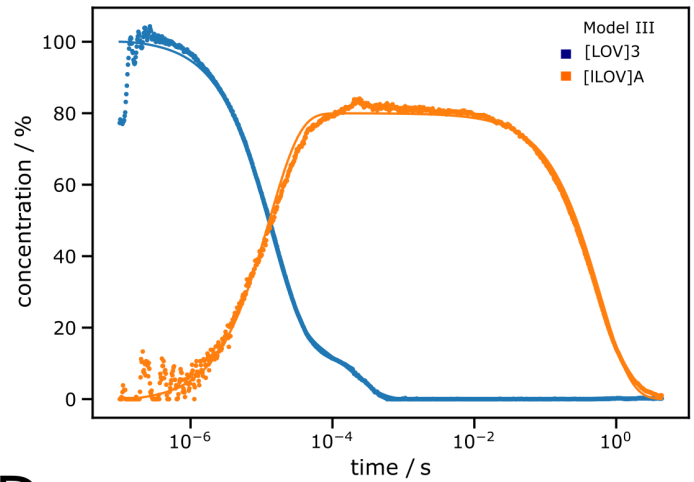

$\mathrm{D}$

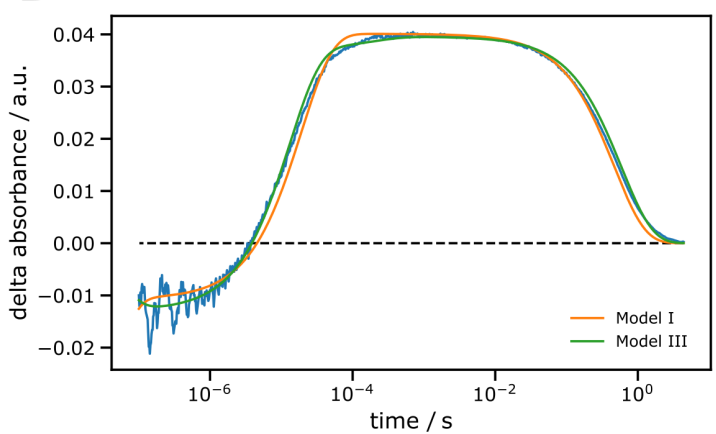

F

Model I:

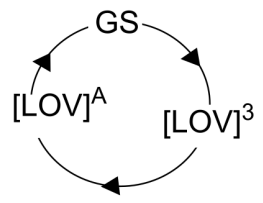

Model III:

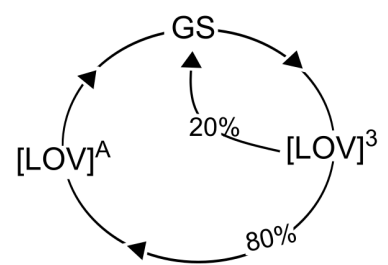

Figure S4: (A), (B) Concentration profiles of the triplet state $[\mathrm{LOV}]^{3}$ (blue trace) and adduct state $[\mathrm{LOV}]^{\mathrm{A}}$ (orange trace) as a function of time. The profiles are obtained by global analysis applied on the time-resolved UV/Vis absorption spectra of DsLOV-M49S assuming a homogenous (panel A - model I) and heterogenous (panel B - model III) triplet state. The homogeneous concentration profile shows a two-step decay of the first spectral component (panel A - blue dots) which is not explained by the model (panel A - blue line). By assuming a heterogeneous triplet state (model III), where one population forms the adduct while the other decays back to the initial ground state, the feature of the two-step decay of the first spectral component (panel B - blue dots) is reproduced by the model (panel B - blue line). (C), (D) The first two singular value decomposition (SVD) components of the fit procedure (blue traces) and the fitted first two singular components (obtained by SVD describing $99 \%$ of the data variance) subjected to global analysis assuming a homogeneous triplet-state population (orange trace - model I) and heterogeneous triplet state population (green trace - model III). The introduction of a heterogeneous triplet state improves the global fit. We obtained the best results by fixing the adduct-forming fraction to values larger than $70 \%$. For the analysis we chose $80 \%$ as reported by Kutta et. al. ${ }^{3}$ (E) Species associated spectra (SAS) for model III. (F) Schematic representation of the models used for global analysis of the time-resolved UV/Vis data. 
Table S2: Time constants $(\tau)$ derived from global analysis (Figure S4) assuming the heterogeneous triplet state (model III in Figure S4F).

\begin{tabular}{|c|c|}
\hline Intermediate state transitions & Time constants $\tau(\mathrm{s})$ \\
\hline$[\mathrm{LOV}]^{3} \rightarrow[\mathrm{LOV}]^{\mathrm{A}}$ & $1.3 \times 10^{-5} \mathrm{~s}$ \\
\hline$[\mathrm{LOV}]^{\mathrm{A}} \rightarrow \mathrm{GS}$ & $5.6 \times 10^{-1} \mathrm{~s}$ \\
\hline$[\mathrm{LOV}]^{3} \rightarrow \mathrm{GS}$ & $1.9 \times 10^{-4} \mathrm{~s}$ \\
\hline
\end{tabular}



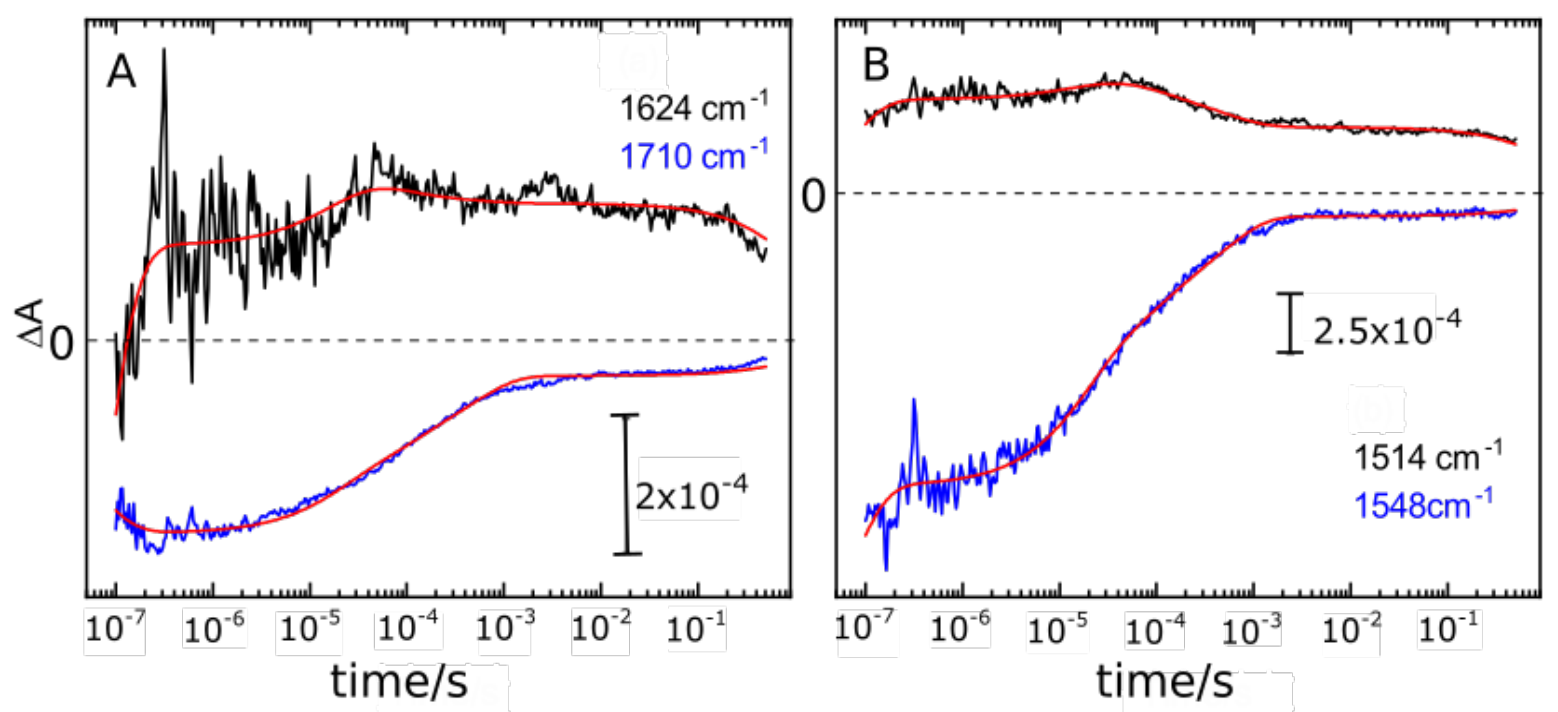

Figure S5: Kinetic traces of selected vibrational bands that arise in the range of $1800-1510 \mathrm{~cm}^{-1}$. (a) The bands at $1624 \mathrm{~cm}^{-1}, 1654 \mathrm{~cm}^{-1}$ and $1710 \mathrm{~cm}^{-1}$ are assigned to the $\mathrm{C}_{2}=\mathrm{O}$ vibrations of [LOV] ${ }^{3}$ and vibrations of $\mathrm{C}_{4}=\mathrm{O}$ of the ground state, respectively. (b) The bands at $1514 \mathrm{~cm}^{-1}$ and $1548 \mathrm{~cm}^{-1}$ originate from the collective $\mathrm{C}=\mathrm{N}$ and $\mathrm{C}=\mathrm{C}$ stretching vibrations of the isoalloxazine ring of $\mathrm{FMN}$.

Unlike the decay of the band at $1654 \mathrm{~cm}^{-1}$ (Figure 4A), the kinetics of other vibrational modes in the 1800$1510 \mathrm{~cm}^{-1}$ range increase in intensity with the first time constants, reaching maximum intensity in the ms time range. The kinetic of $1514 \mathrm{~cm}^{-1}$ (black trace in Figure S5B) is characteristic of the $\mathrm{CN}$ and CC vibrational modes which rises upon adduct-state formation ${ }^{5}$. The $1514 \mathrm{~cm}^{-1}$ kinetic already presents a strong positive signal in early states, which increases to a maximum intensity, followed by a sharp decay. The bands at 1624 $\mathrm{cm}^{-1}$ and $1654 \mathrm{~cm}^{-1}$ (Figure 4A) are assigned to the carbonyl vibrations of the triplet-excited state and decay upon adduct formation due to a shift to higher wavenumbers ${ }^{6-7}$. At early time points, the $1624 \mathrm{~cm}^{-1}$ kinetic (black trace, panel A, Figure S5) shows just a small positive signal with a time evolution similar to the kinetic of the band at $1514 \mathrm{~cm}^{-1}$. Since the modes at 1654 and $1624 \mathrm{~cm}^{-1}$ originate from $\mathrm{C}=\mathrm{O}$ vibrations, a similar behavior in the kinetics was expected. However, the differences can be due to the fact that the band at 1654 $\mathrm{cm}^{-1}$ mainly contains contributions from the $\mathrm{C}_{4}=\mathrm{O}$ stretching mode, whereas the band at $1624 \mathrm{~cm}^{-1}$ contains a contribution from the $\mathrm{C}=\mathrm{C}$ stretching mode of ring $\mathrm{I}$. The band at $1548 \mathrm{~cm}^{-1}$ is due to the collective $\mathrm{C}=\mathrm{N}$ and $\mathrm{C}=\mathrm{C}$ stretching vibrations of the isoalloxazine ring of $\mathrm{FMN}$ and exhibits a time course (blue trace in Figure $\mathrm{S} 5 \mathrm{~B}$ ) that is negative in the ns time range to relax back in the ms time range. Similar kinetics are recorded at $1710 \mathrm{~cm}^{-1}$ which is the band of the $\mathrm{C}_{4}=\mathrm{O}$ vibration of ground-state FMN. The latter is shifted to higher wavenumbers $\left(1726 \mathrm{~cm}^{-1}\right)$ upon formation of the adduct state. 


\section{Lifetime density analysis of the time-resolved IR data}

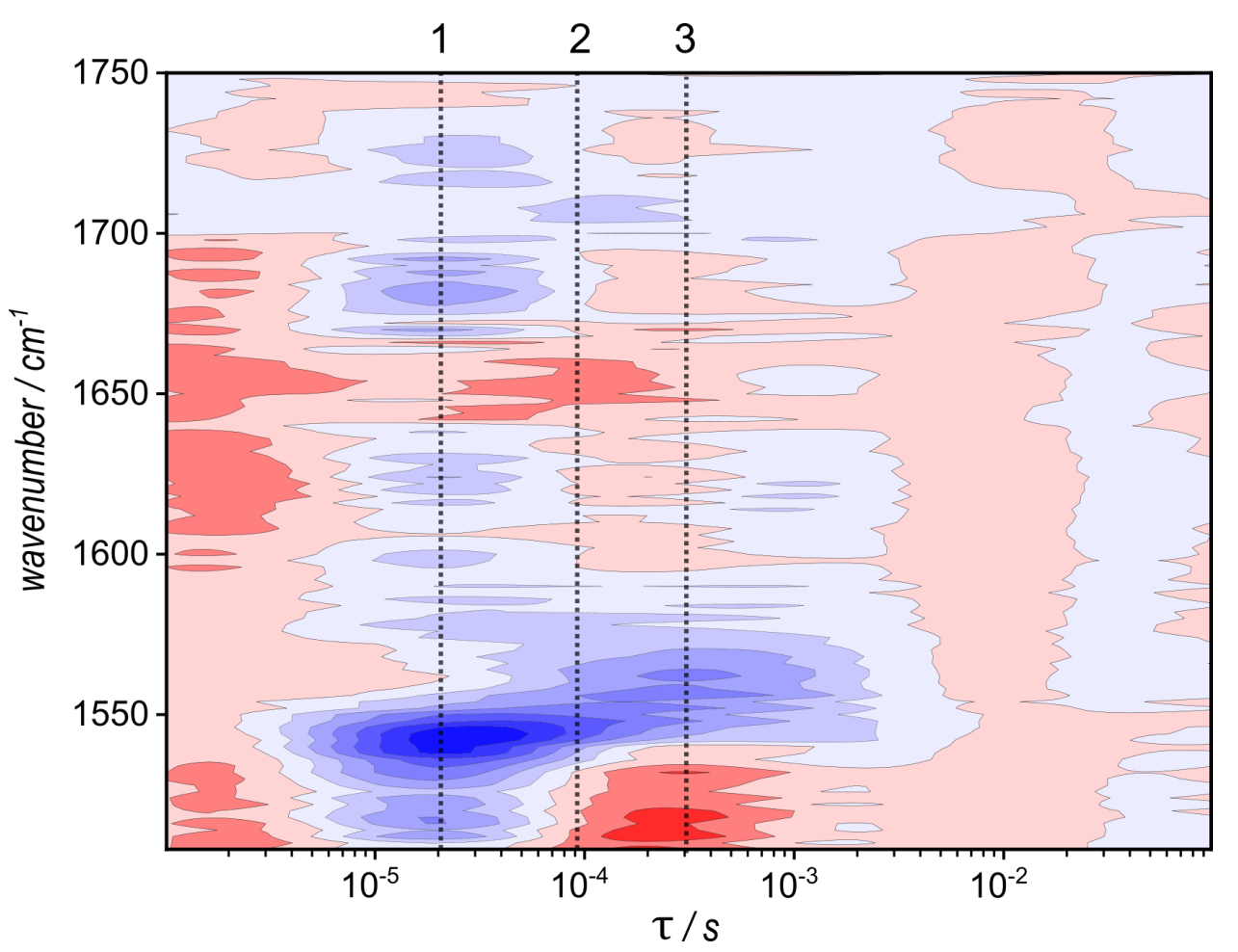

Figure S6: Lifetime density analysis (LDA) of the time-resolved IR data of DsLOV-M49S. LDA is advantageous in comparison to other analysis methods because no photocycle model needs to be predefined, which minimizes the introduction of bias. In $\mathrm{LDA}^{25}$, the following equation

$$
\min |D * x-A|
$$

where $\mathbf{A}$ is the data matrix and $\mathbf{D}$ contains a finite number of exponential decays $\left(e^{-t / \tau i}\right)$, is minimized in favor of $\boldsymbol{x}$. Due to a huge number of lifetimes, we used the Tikhonov regularization. The resulting prefactors are independent for each wavenumber and are plotted here as a contour plot. Calculations were done with a home-built algorithm written in Python with 200 logarithmically spaced time constants ranging from $10^{-7}$ up to $10^{-1} \mathrm{~s}$. The more intense blue and red areas denote a high contribution of exponential decays at these wavenumbers. The vertical lines denote possible transitions of intermediates or decays back to the ground state associated with numerous spectral changes. The first high lifetime density is $20 \mu \mathrm{s}$, with spectral changes associated at $\sim 1725 \mathrm{~cm}^{-1}$ assigned to the $\mathrm{C}_{4}=\mathrm{O}$ vibration during adduct-state formation. At third vertical line, spectral changes are associated at $\sim 1725 \mathrm{~cm}^{-1}$, plus spectral changes around $\sim 1555 \mathrm{~cm}^{-1}$. It seems that the adduct state experiences a further change. This is contrasted by the lifetime density around the second vertical line, where spectral changes at different wavenumbers are associated. Remarkably, at $\sim 1710 \mathrm{~cm}^{-1}$ and around $1665 \mathrm{~cm}^{-1}$, which are assigned to the $\mathrm{C}_{2}=\mathrm{O}$ vibration in the ground state and $\mathrm{C}_{4}=\mathrm{O}$ of the triplet state. This suggests that there is an additional concurrent decay from the triplet directly back to the ground state. 


\section{Kinetic models}

A
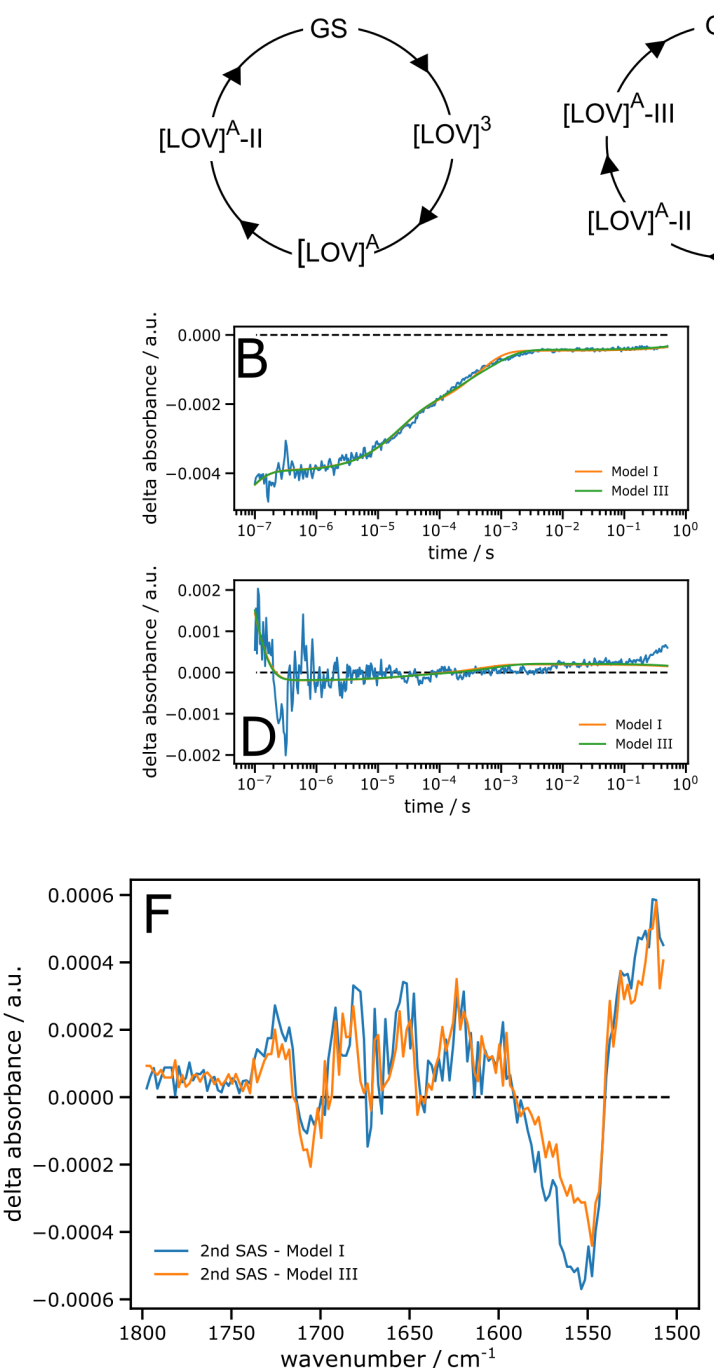

Model II:

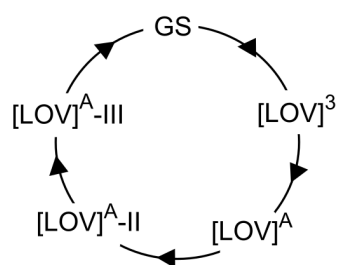

Model III:

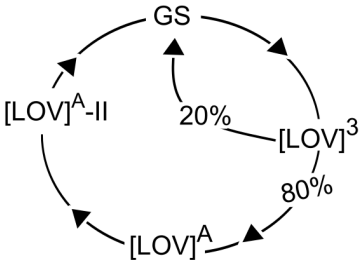

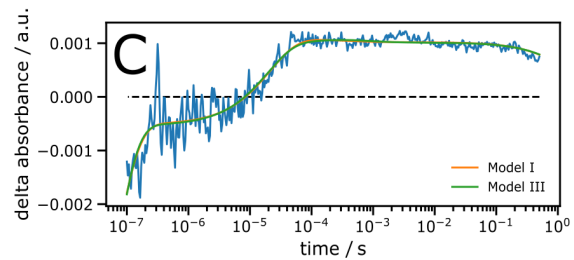
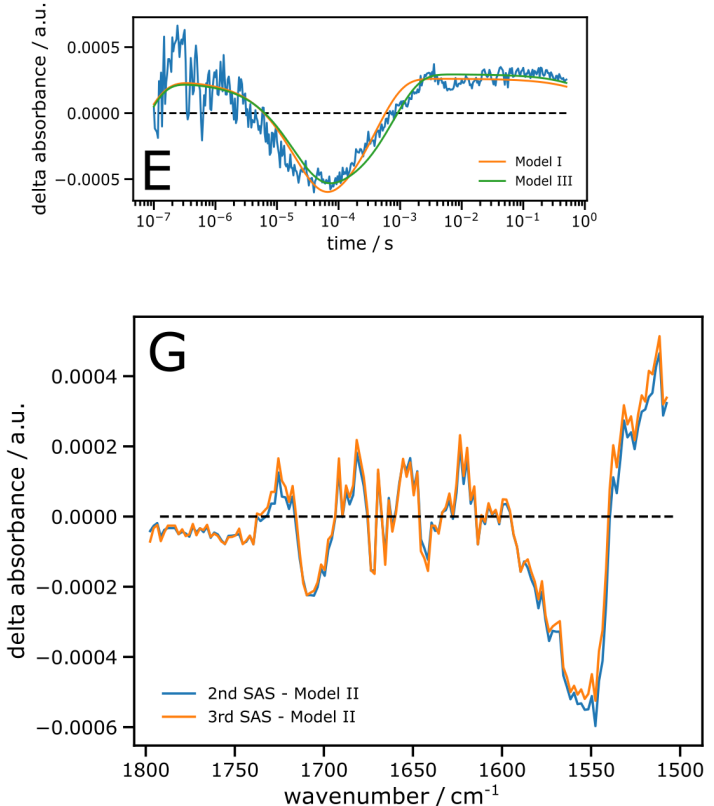

Figure S7: (A) Reaction models used for global target analysis of the time-resolved IR experiments with $[\mathrm{LOV}]^{3}$ for the triplet and $[\mathrm{LOV}]^{\mathrm{A}}$ for the adduct state. The analysis was performed with a home-built algorithm written in Python where a certain number of singular components are fitted with a defined number of exponential decays. Model I and II are simple sequential reaction schemes, where model I has three components and model II has four components, before the decay back to the ground state (GS). Model II interprets the spectral changes associated with the second high lifetime density of the LDA analysis (Figure S6, $2^{\text {nd }}$ vertical line) as an additional intermediate. Model III assumes heterogeneity in the triplet state with fixed populations. This means that part of the triplet state decays back to the ground state and the other part goes through two more intermediates $\left([\mathrm{LOV}]^{\mathrm{A}}\right.$ and $\left.[\mathrm{LOV}]^{\mathrm{A}}-\mathrm{II}\right)$ before the decay to the ground state. (B), (C), (D), (E) The first four singular components (blue traces), obtained by singular value decomposition, subjected to the fit procedure, representing $95 \%$ of the variance. The orange and green traces are a fit with a sum of exponentials resulting from global analysis assuming a homogeneous tripletstate population (orange trace - model I) and the heterogeneous triplet state population (green trace - model III). Global analysis using models I and III yielded similar results, although the abstract time traces are slightly better fitted with model III. (F) Spectrum associated with the second species (assigned to [LOV] ${ }^{\mathrm{A}}$ ) considering the homogeneous triplet-state population (blue trace, model I) and heterogeneous triplet-state population (orange trace - model III). (G) Second SAS corresponding to [LOV] ${ }^{\mathrm{A}}$ (blue trace) and third SAS corresponding to [LOV] ${ }^{\mathrm{A}}$-II (orange trace) of model II. With this model, the fit did not converge satisfactorily. We kept the first three time constants to $2.1 \times 10^{-5} \mathrm{~s}, 9.5 \times 10^{-5} \mathrm{~s}$ and $4.1 \times 10^{-4} \mathrm{~s}$ to calculate the 
SAS which turned out to be very similar. Thus, introduction of an additional intermediate was not justified.

Considering these points in addition to the results of the LDA (Figure S6) and global analysis of the UV/Vis data (Figure S4), we conclude that model III describes our data best. We also varied the starting populations and obtained good results for $70 \%$ and above for the $[\mathrm{LOV}]^{3} \rightarrow[\mathrm{LOV}]^{\mathrm{A}}$ pathway. Yet, since Kutta et al. ${ }^{3}$ have determined an 80:20 ratio, we decided to use these values for our further analysis

Table S3: Time constants $(\tau)$ obtained from the global analysis assuming a homogeneous triplet-state population (model I) and the heterogeneous triplet-state population (model III).

\begin{tabular}{|c|c|c|}
\hline Intermediate state transitions & $\tau(\mathrm{s})$ Model I & $\tau(\mathrm{s})$ Model III \\
\hline$[\mathrm{LOV}]^{3} \rightarrow[\mathrm{LOV}]^{\mathrm{A}}$ & $2.1 \times 10^{-5} \mathrm{~s}$ & $1.8 \times 10^{-5} \mathrm{~s}$ \\
\hline$[\mathrm{LOV}]^{\mathrm{A}} \rightarrow[\mathrm{LOV}]^{\mathrm{A}-\mathrm{II}}$ & $4.1 \times 10^{-4} \mathrm{~s}$ & $5.1 \times 10^{-4} \mathrm{~s}$ \\
\hline$[\mathrm{LOV}]^{\mathrm{A}-I I} \rightarrow \mathrm{GS}$ & $1.9 \mathrm{~s}$ & $1.7 \mathrm{~s}$ \\
\hline$[\mathrm{LOV}]^{3} \rightarrow \mathrm{GS}$ & - & $8.3 \times 10^{-5} \mathrm{~s}$ \\
\hline
\end{tabular}




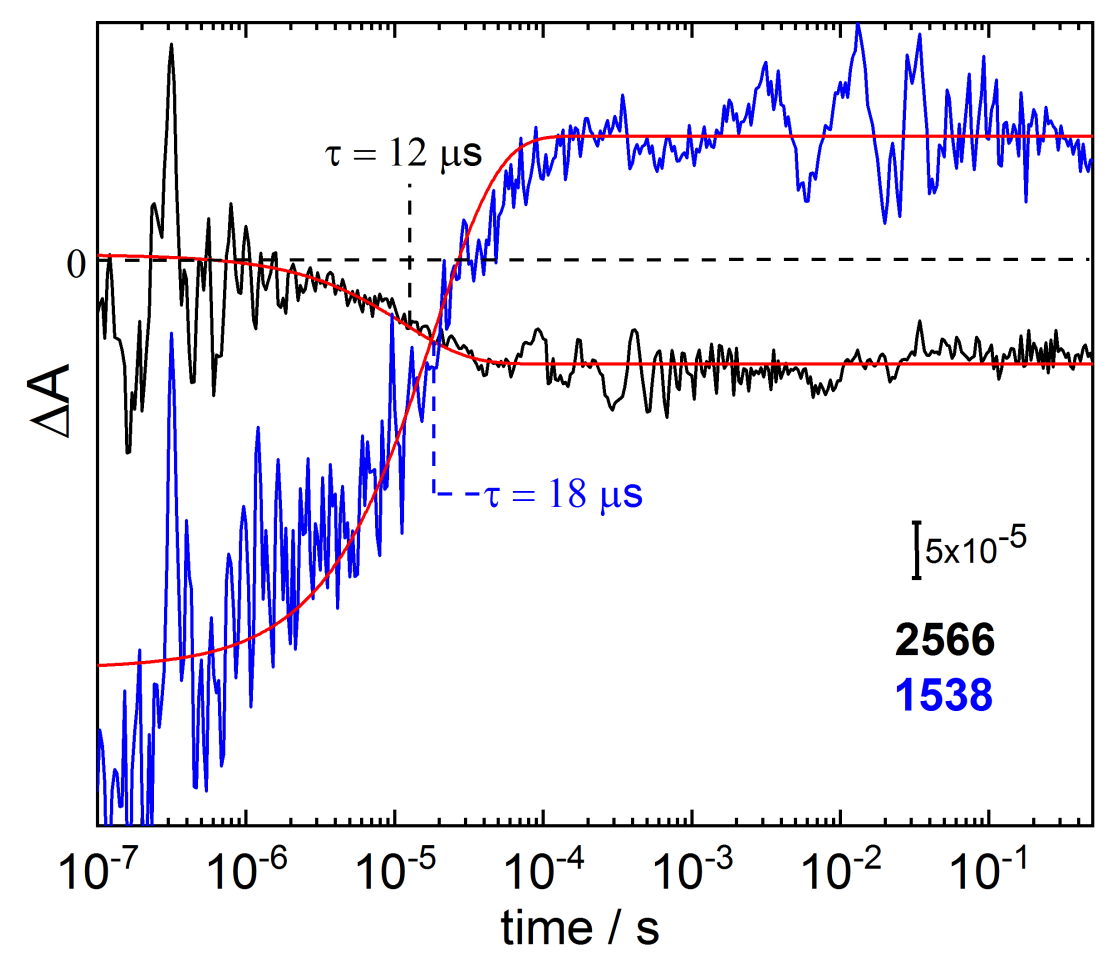

Figure S8: Kinetics of proton dissociation from C72 (black trace, replotted from Figure 3B) and formation of the adduct state (blue trace). The band at $1538 \mathrm{~cm}^{-1}$ has been assigned to a vibrational mode with strong $\mathrm{C}_{4 a}-\mathrm{N}_{5}$ stretching vibrational character that arises after the transition of $\mathrm{C}_{4 \mathrm{a}}$ to the non-planar sp ${ }^{3}$ tetrahedral configuration ${ }^{2}$. Consequently, this kinetic is a proxy for the formation of the adduct state. The single exponential fits for both traces are shown in red and the time constants of each individual exponential fit are indicated in the figure. 


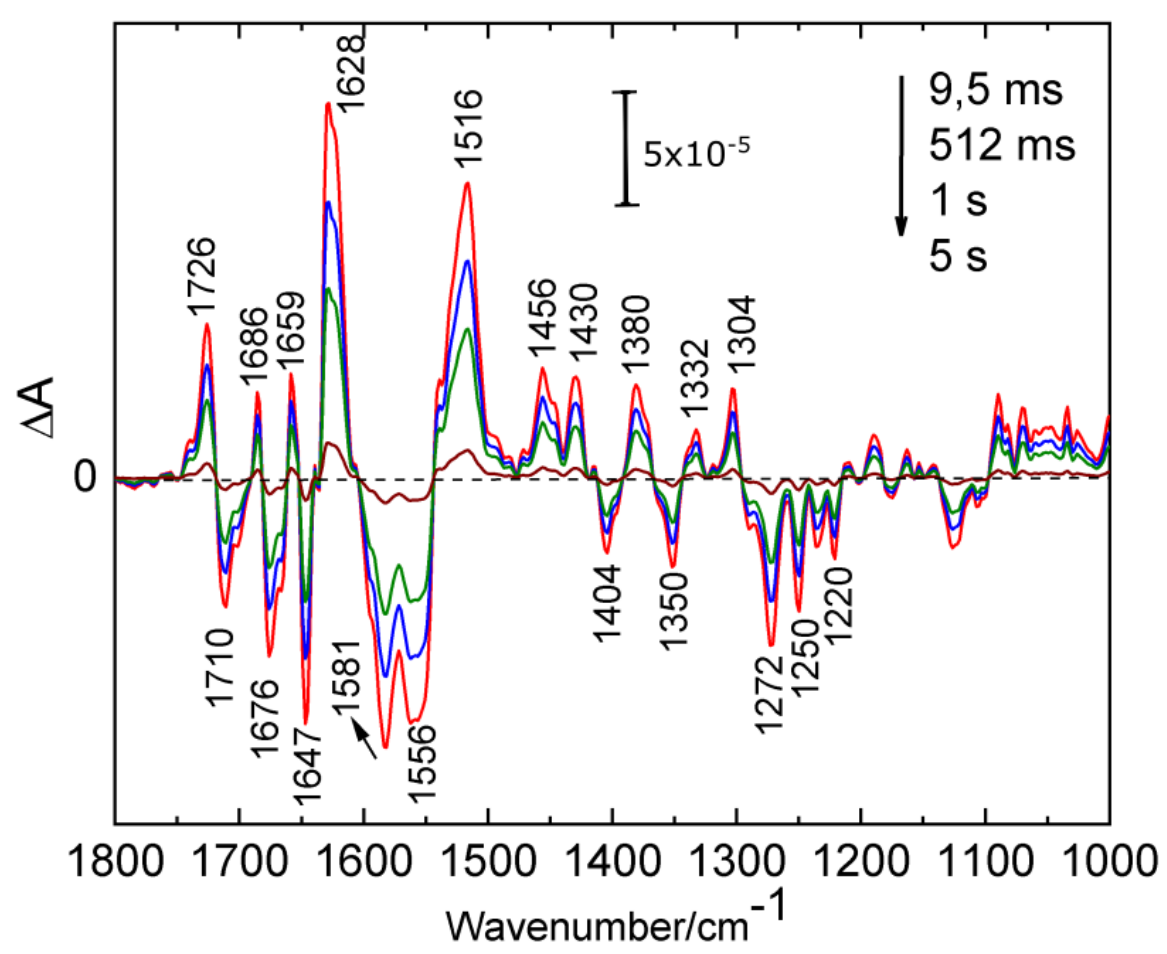

Figure S9: Sequence of FTIR difference spectra recorded in the millisecond time range of DsLOV-M49S by rapid-scan FTIR spectroscopy after blue light excitation. Data was collected in the range of $9.5 \mathrm{~ms}$ to 10 $\mathrm{s}$ and shows the recovery of the DsLOV-M49S to the initial dark state. Kinetic traces at single frequencies have been extracted and appended to the QCL data to expand the time range of the latter into the ms and $\mathrm{s}$ time range (Figure 4).

The time-resolved rapid-scan data was collected across the $1800-1000 \mathrm{~cm}^{-1}$ range using a Vertex $80 \mathrm{~V}$ spectrometer (Bruker) at a spectral resolution of $4 \mathrm{~cm}^{-1}$. The sample was excited every $10 \mathrm{~s}$ with a $10 \mathrm{~ns}$ blue laser pulse $(450 \mathrm{~nm})$ from an optical parametric oscillator $(\mathrm{OPO})$ driven by the third harmonic of a Nd:YAG laser. Laser energy was adjusted to $2.5-3 \mathrm{~mJ}$ per pulse. To improve the signal-to-noise ratio, experiments were repeated 500 times. 


\section{Kinetic isotope effect}
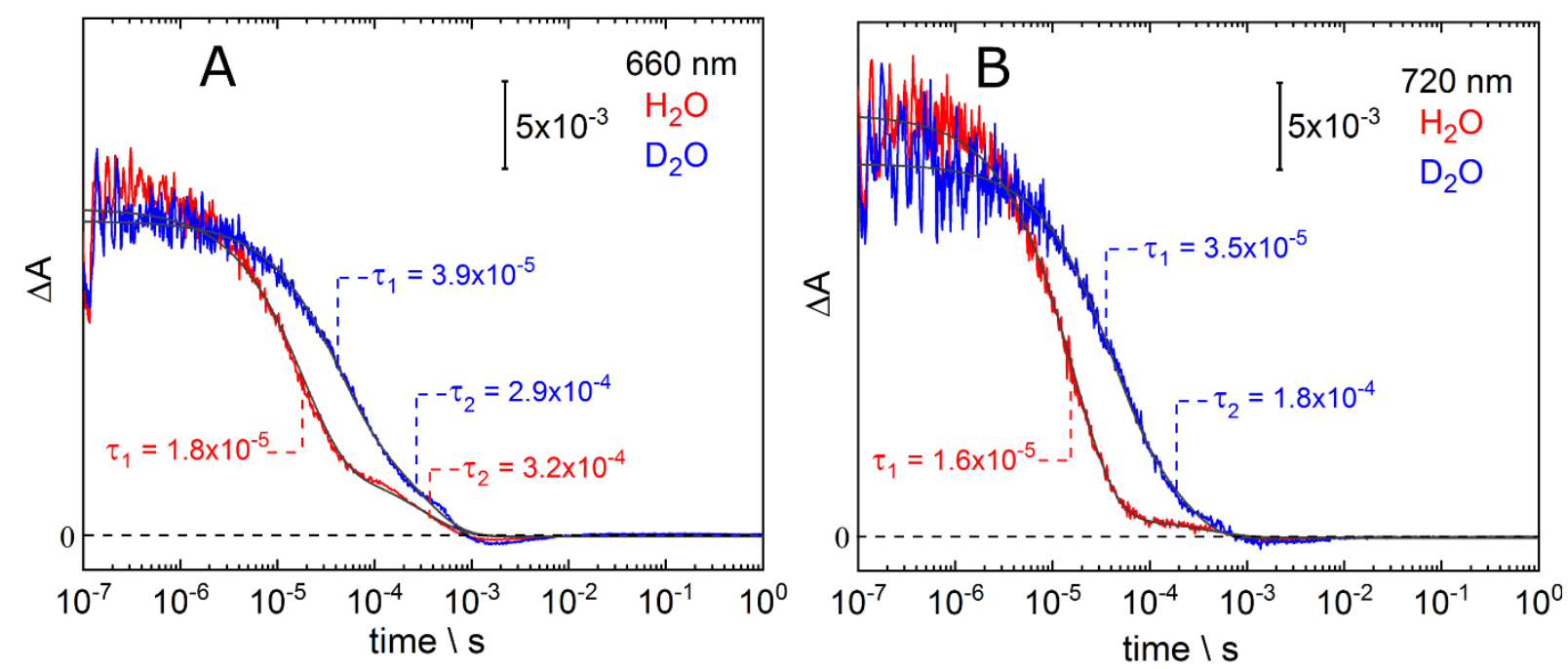

Figure S10: Decay kinetics of the triplet state in $\mathrm{H}_{2} \mathrm{O}$ (red traces) and $\mathrm{D}_{2} \mathrm{O}$ (blue traces) monitored at 660 $\mathrm{nm}$ (A) and $720 \mathrm{~nm}$ (B). The kinetic isotope effect KIE is 2-3 as calculated by taking the ratio of the decay times in $\mathrm{D}_{2} \mathrm{O}$ and $\mathrm{H}_{2} \mathrm{O}$. The KIE of DsLOV-M49S is less than in LOV2 of phototropin $1(\mathrm{KIE}=5)^{1}$. 


\section{References}

1. Corchnoy, S. B.; Swartz, T. E.; Lewis, J. W.; Szundi, I.; Briggs, W. R.; Bogomolni, R. A., Intramolecular proton transfers and structural changes during the photocycle of the LOV2 domain of phototropin 1. J Biol Chem 2003, 278 (2), 724-31.

2. Swartz, T. E.; Wenzel, P. J.; Corchnoy, S. B.; Briggs, W. R.; Bogomolni, R. A., Vibration spectroscopy reveals light-induced chromophore and protein structural changes in the LOV2 domain of the plant blue-light receptor phototropin 1. Biochemistry 2002, 41 (23), 7183-9.

3. Kutta, R. J.; Magerl, K.; Kensy, U.; Dick, B., A search for radical intermediates in the photocycle of LOV domains. Photochem Photobiol Sci 2015, 14 (2), 288-99.

4. Ataka, K.; Hegemann, P.; Heberle, J., Vibrational spectroscopy of an algal Phot-LOV1 domain probes the molecular changes associated with blue-light reception. Biophys J 2003, 84 (1), $466-74$.

5. Pfeifer, A.; Majerus, T.; Zikihara, K.; Matsuoka, D.; Tokutomi, S.; Heberle, J.; Kottke, T., Timeresolved Fourier transform infrared study on photoadduct formation and secondary structural changes within the phototropin LOV domain. Biophys J 2009, 96 (4), 1462-70.

6. Iwata, T.; Nozaki, D.; Sato, Y.; Sato, K.; Nishina, Y.; Shiga, K.; Tokutomi, S.; Kandori, H., Identification of the $\mathrm{C}=\mathrm{O}$ stretching vibrations of FMN and peptide backbone by $13 \mathrm{C}$-labeling of the LOV2 domain of Adiantum phytochrome3. Biochemistry 2006, 45 (51), 15384-91.

7. Thöing, C.; Pfeifer, A.; Kakorin, S.; Kottke, T., Protonated triplet-excited flavin resolved by step-scan FTIR spectroscopy: implications for photosensory LOV domains. Phys Chem Chem Phys 2013, 15 (16), 5916-26.

8. Martin, C. B.; Tsao, M. L.; Hadad, C. M.; Platz, M. S., The reaction of triplet flavin with indole. A study of the cascade of reactive intermediates using density functional theory and time resolved infrared spectroscopy. J Am Chem Soc 2002, 124 (24), 7226-34.

9. Bowman, W. D.; Spiro, T. G., Normal mode analysis of lumiflavin and interpretation of resonance Raman spectra of flavoproteins. Biochemistry 1981, 20 (11), 3313-8.

10. Martin, C. B.; Shi, X. F.; Tsao, M. L.; Karweik, D.; Brooke, J.; Hadad, C. M.; Platz, M. S., The photochemistry of riboflavin tetraacetate and nucleosides. A study using density functional theory, laser flash photolysis, fluorescence, UV-Vis, and time resolved infrared spectroscopy. Journal of Physical Chemistry B 2002, 106 (39), 10263-10271.

11. Abe, M.; Kyogoku, Y., Vibrational Analysis of Flavin Derivatives - Normal Coordinate Treatments of Lumiflavin. Spectrochimica Acta Part a-Molecular and Biomolecular Spectroscopy 1987, 43 (8), 1027-1037.

12. Zheng, Y.; Dong, J.; Palfey, B. A.; Carey, P. R., Using Raman spectroscopy to monitor the solvent-exposed and "buried" forms of flavin in p-hydroxybenzoate hydroxylase. Biochemistry 1999, 38 (51), 16727-32.

13. Benecky, M. J.; Copeland, R. A.; Spiro, T. G., Resonance Raman spectra of flavin semiquinones stabilized by N5 methylation. Biochim Biophys Acta 1983, 760 (1), 163-8.

14. Tegoni, M.; Gervais, M.; Desbois, A., Resonance Raman study on the oxidized and anionic semiquinone forms of flavocytochrome b2 and L-lactate monooxygenase. Influence of the structure and environment of the isoalloxazine ring on the flavin function. Biochemistry 1997, 36 (29), $8932-46$. 15. Dutta, P. K.; Spencer, R.; Walsh, C.; Spiro, T. G., Resonance Raman and coherent anti-stokes Raman scattering spectra of flavin derivatives. Vibrational assignments and the zwitterionic structure of 8-methylamino-riboflavin. Biochim Biophys Acta 1980, 623 (1), 77-83.

16. Kitagawa, T.; Nishina, Y.; Kyogoku, Y.; Yamano, T.; Ohishi, N.; Takai-Suzuki, A.; Yagi, K., Resonance Raman spectra of carbon-13- and nitrogen-15-labeled riboflavin bound to egg-white flavoprotein. Biochemistry 1979, 18 (9), 1804-8.

17. Nishina, Y.; Shiga, K.; Horiike, K.; Tojo, H.; Kasai, S.; Matsui, K.; Watari, H.; Yamano, T., Resonance Raman spectra of semiquinone forms of flavins bound to riboflavin binding protein. $J$ Biochem 1980, 88 (2), 411-6. 
18. Su, Y.; Tripathi, G. N. R., Time-Resolved Resonance Raman Observation of Protein-Free Riboflavin Semiquinone Radicals. Journal of the American Chemical Society 1994, 116 (10), 44054407.

19. Hazekawa, I.; Nishina, Y.; Sato, K.; Shichiri, M.; Miura, R.; Shiga, K., A Raman study on the $C(4)=0$ stretching mode of flavins in flavoenzymes: hydrogen bonding at the $C(4)=0$ moiety. $J$ Biochem 1997, 121 (6), 1147-54.

20. Murgida, D. H.; Schleicher, E.; Bacher, A.; Richter, G.; Hildebrandt, P., Resonance Raman spectroscopic study of the neutral flavin radical complex of DNA photolyase from Escherichia coli. Journal of Raman Spectroscopy 2001, 32 (6-7), 551-556.

21. M. Abe, Y. K., T. Kitagawa, K. Kawano, N. Ohishi, A. Takai-Suzuki, and K. Yagi, Infrared spectra and molecular association of lumiflavin and riboflavin derivatives. Spectrochimica Acta 1986, 42A(9), 1059-68.

22. Nishina, Y.; Kitagawa, T.; Shiga, K.; Horiike, K.; Matsumura, Y.; Watari, H.; Yamano, T., Resonance Raman spectra of riboflavin and its derivatives in the bound state with egg riboflavin binding proteins. J Biochem 1978, 84 (4), 925-32.

25. Dorlhiac, G.F.; Fare, C.; van Thor, J.J. PyLDM - An open source package for lifetime density analysis of time-resolved spectroscopic data. PLoS Comput Biol. 2017, 13(5):e1005528. 